\title{
Optimizing the Construction of College English Mobile Teaching Oriented by Industry Demand
}

\author{
Huijun Fu, Feipeng Li \\ Baoding University, Baoding, China \\ Email: 496472980@qq.com
}

How to cite this paper: Fu, H. J., \& Li, F. P. (2021). Optimizing the Construction of College English Mobile Teaching Oriented by Industry Demand. Creative Education, 12, 737-746.

https://doi.org/10.4236/ce.2021.124052

Received: March 16, 2021

Accepted: April 10, 2021

Published: April 13, 2021

Copyright $\odot 2021$ by author(s) and Scientific Research Publishing Inc. This work is licensed under the Creative Commons Attribution International License (CC BY 4.0).

http://creativecommons.org/licenses/by/4.0/

(c) (i) Open Access

\begin{abstract}
With the development of the Internet and mobile terminal, mobile teaching is a new trend of reform in college English teaching. In mobile teaching, industry demand should also be taken into account, which is in accordance with the running target of Baoding University. In order to cultivate more applied talents, the paper is oriented by industry demand and explores the optimizing construction of college English mobile teaching in Baoding University, Hebei Province, China. The study employs quantitative and qualitative research design. First, an interview is designed to investigate industry demand of travel agencies. Second, a questionnaire involving 168 freshmen majoring in tourism aims to investigate the status quo of college English mobile teaching. The data collected from the interview and the questionnaire reveal the existing problems. Based on those problems, the researchers have in-depth discussions on the causes and related improvements. Then teaching reform of college English mobile teaching oriented by industry demand is carried out. Third, the other interview intends to check the effect of teaching reform. It is hoped that the study can realize the optimization of teaching environment, teaching methods, teacher-student relations, students' autonomous learning and cultivation of applied talents.
\end{abstract}

\section{Keywords}

College English, Mobile Teaching, Industry Demand

\section{Introduction}

With the development of social economy, mobile communication technology has gained its unprecedented developing space. Various mobile devices such as computers, mobile phones, etc. are applied to students' common life. According to China's Education Informatization 2.0 Action Plan (2018), education infor- 
matization is the basic content and the significant sign of educational modernization. It should explore the advantages of educational technology, innovate the traditional mode, and promote the deep integration of new technology and education. College English Teaching Guideline (2020) also highlights the implication of information technology and smart technology to college English teaching. It points out that information technology has become an important means of foreign language teaching (He, 2020).

Under this circumstance, college English teaching should also make some revolutions to meet the development of the times. Mobile teaching is a trend. It should be integrated into traditional college English teaching, thus making up for the disadvantages of traditional college English teaching. Meanwhile, the study is conducted at Baoding University, an application-oriented local undergraduate institute. Based on this orientation, the cultivation of talents should meet the demands of different industries, so as to enhance the competitiveness of talents and better serve the development of local economy.

To combine industry demand with college English mobile teaching is an innovation of college English teaching. The study is expected to activate students' learning interest and enthusiasm, and promote students' English language competence. The research paper is divided into four parts. Part 1 is the introduction. Part 2 is a literature review. Part 3 is the methodology part. In this part, how the study is developed is presented in detail. Part 4 is the research result and related discussions. Part 5 is the conclusion of the study. It is hoped to get some enlightenment for College English teaching.

\section{Literature Review}

Needs analysis has great significance to English teaching. In the 1920s, Michael West first introduced the concept of "needs" in India. He discovered the needs of high school English learners were not specified precisely, and learners were still in a state of TENOR (Teaching English for No Obvious Reason). "Needs" cover what learners will be required to do with the foreign language in the target situation and how learners might best master the language during the period learning (Rahman, 2015). According to Munby (1978), needs analysis is to adjust language courses to meet different needs of students who have different levels, countries and purposes. He put forward Target Situation Analysis. Hutchinson \& Waters (1987) held that "any language course should be based on needs analysis". Needs were defined as necessities, wants and lacks. They divided needs into target needs and learning needs. Brindley (1989) described needs as "the gap between what the learners' actual needs are and what should be taught to them". He thought that needs should cover objective needs and subjective needs. Needs analysis mainly includes social needs and individual needs (Shu, 2004). The former is the need for foreign language proficiency from society and employers; the latter is the gap between students' actual proficiency and their expected proficiency. 
Austrian scholar Linder and Bruck (2004) put forward the concept of "microlearning". It refers to the process in which learners obtain microcontent by means of micromedia. In the process of mobile teaching, teachers can adopt various mobile devices, such as computers, laptops, mobile phones. Ekanayake and Wishart (2015) evaluated the implementation of mobile phones in a professional development training context and discussed how the integration of mobile devices could positively impact the learners. Teachers can also use several teaching platforms. Mobile teaching has many benefits. In mobile learning environment, students can search for real-time answers to difficult questions, and search for various types of learning resources, rich in content and interesting, which can help stimulate students' interest and promote students' fragmentation learning (Keengwe \& Bhargava, 2014). At present, related studies on college English mobile teaching have two characteristics: 1) Studies conducted based on one theory. For example, Constructivism, Distributed Cognitive Theory, etc.; 2) Related studies based on one platform, such as Moso Teach App, and WeChat.

Through searching on CNKI (China National Knowledge Infrastructure), there are 25 essays combining industry demand with college English teaching, involving discussions about Situational Teaching Method, Cooperative Learning, Macroscopic Teaching Mode. However, there's still a blank as to the study on optimizing the construction of college English mobile teaching oriented by industry demand. In the future, with the construction of application-oriented local undergraduate institute and the development of mobile teaching, this topic will deserve more attention.

\section{Methodology}

Oriented by industry demand, the study aims to optimize the mobile teaching of college English. The study can meet the requirements proposed by College Foreign Language Teaching Steering Committee that college English teaching should serve the running objectives of the university, talents cultivation objectives of the college, and students' personalized demand. It can also meet the practical transformation development of Baoding University and the promotion of students' English comprehensive ability.

\subsection{Research Questions}

In view of its necessity, the study is carried out mainly surrounding the following two questions:

Question 1 is the status quo of the industry's demand for English competence of talents.

Question 2 is the status quo of the mobile teaching of college English in Baoding University.

Based on the above two questions, the study adopts both the quantitative and qualitative research methods. Through the research, some related problems will be revealed, then the optimization of the construction of college English mobile 
teaching oriented by industry demand will get further explored.

\subsection{Participants}

Altogether one hundred and sixty-eight freshmen from Baoding University are chosen as the research respondents. The respondents are from two intact classes of College of Geography and Tourism. Each class has 84 students. Their major is tourism, and they are aged between 18 to 19 . They have the normal grade distribution. To avoid the disturbance from irrelevant variables, one English teacher is assigned to teach the two classes. In the first semester of the junior year, students have used some mobile devices and gained some English knowledge through mobile learning.

\subsection{Research Instruments}

The research instruments include two interviews and one questionnaire. First, one interview is carried out among executives of 20 travel agencies. It aims to grasp the demand of the tourist industry for students' English competence. The other interview is carried out with 40 participants after the mobile teaching reform. It aims to test whether the reform is effective or not. Second, a questionnaire is carried out with all the participants. It is designed to learn about the status quo of college English mobile teaching, thus trying to reveal some problems and making correspondent improvements.

\subsection{Research Procedures}

The research lasts for over one year from Nov. 2019 to Mar. 2021.

First, at the beginning of the research, an interview was conducted among executives of 20 travel agencies from Baoding, Hebei Province, China. To master the overall situation of the travel industry's demand for talents, researchers have consulted the local tourism authority to select different levels of travel agencies. The interview includes 8 questions. By analyzing the result of the interview, researchers hope to get an overall mastery of the industry demand.

Second, to investigate the status quo of college English mobile teaching in Baoding University, researchers carried out a questionnaire among the 168 respondents. The Likert scale is employed in this questionnaire. There are altogether five choices in each item. They are arranged from $\mathrm{A}$ to $\mathrm{E}$. $\mathrm{A}=$ always, $\mathrm{B}=$ usually, $\mathrm{C}=$ sometimes, $\mathrm{D}=$ seldom, and $\mathrm{E}=$ never. Respondents need to choose one of the five choices in each item. Altogether 168 copies of questionnaire have been distributed and recollected with the same amount.

Third, after the data collection of both the interview and the questionnaire, researchers analyzed the data, discovered the problems existed in traditional teaching and reflected on the improvements of present mobile teaching of college English.

Fourth, after the reflection, researchers made related teaching reform and carried out the new teaching practice. From the second semester of the junior year 
to the first semester of the sophomore year, students were taught college English both in traditional teaching mode and mobile teaching mode. The mobile teaching mode has been optimized. It is oriented by industry demand in order to cultivate more applied talents.

Fifth, an interview was followed by the teaching practice. A total of 40 respondents joined this interview, which covers five questions. The interview mainly focuses on checking the teaching effect of college English mobile teaching oriented by industry demand, thus helping researchers make further reflection on the related teaching plan.

\section{Results and Discussion}

\subsection{Results and Discussion about Industry Demand}

Table 1 shows the data of the interview about industry demand.

According to the choices made by executives of 20 travel agencies, it can be seen from the first two questions that all the travel agencies have requirements for employees' English competence, and 17 travel agencies require employees hold CET-4 or CET-6 certificates. Three travel agencies have no certificate requirement because they're relatively new travel agencies and their businesses haven't further expanded yet. Therefore, employees need to have certain English competence, which is basic and necessary when they get into new careers. They need to grasp basic English knowledge.

In Question 3, 18 executives of 20 travel agencies hold that new employees lack English knowledge about the industry. Two executives chose "no", which may relate to employees' personal English ability. This result is a reminder that English teachers should teach students some basic ESP (i.e. English for specific purposes) knowledge in college English teaching, so that students can learn more English knowledge about the industry before getting employed.

Table 1 . The interview about industry demand.

\begin{tabular}{lcc}
\hline \multicolumn{1}{c}{ Questions } & Feedbacks \\
\cline { 2 - 3 } & Yes & No \\
\hline $\begin{array}{l}\text { 1) Do your travel agency has requirements for employees' English } \\
\text { competence? }\end{array}$ & 20 & 0 \\
2) Do new employees need to have CET-4 or CET-6 certificates? & 17 \\
3) Do new employees lack English knowledge about the industry? & 18 \\
4) Can new employees flexibly use industry terms in English? & 5 \\
5) Can new employees introduce scenic spots in English? & 3 \\
6) Have new employees grasped qualified industry-related English \\
listening and speaking skills?
\end{tabular}


Question 4 to 6 are designed to investigate new employees' specific English abilities about the industry. Question 4 shows 15 executives of the 20 travel agencies hold new employees cannot flexibly use industry terms in English. Five executives chose "yes". Probably it is because different executives have different control as to the word "flexibly". In Question 5, 17 executives hold new employees cannot introduce scenic spots in English. Although 3 executives chose "yes" to this question, this truly reflects the status quo of new employees' English comprehensive abilities. They both lack English general knowledge and specific knowledge. In Question 6, 18 executives hold new employees have not grasped qualified industry-related English listening and speaking skills, and only 2 executives hold the opposite opinion. Industry-related English listening and speaking skills can reflect employees' communicative competence, and influence their communicative and interactive effect with customers. All in all, English teachers should enhance students' specific English abilities about the industry, thus students can become competent for future jobs.

In Question 7, 20 executives hold that new employees have not fully understood Chinese and Western culture and different customs. As to tourism, mastering cultural difference and different customs is quite important. It also meets the demand of tourism. Learning culture is an important aspect of learning languages. In college English teaching, teachers should pay attention to the comparison of Chinese culture and Western culture, lead students to learn more about different customs, and cultivate students' intercultural communication competence.

Question 8 shows new employees cannot design international travel routes. This also reflects that new employees cannot completely grasp the geography of foreign countries, and they lack related experiences for their jobs. Meanwhile, they also lack cultural knowledge. In college English teaching, teachers should help students expand their knowledge and launch some industry-related English activities.

\subsection{Results and Discussion about Mobile Teaching of College English}

Table 2 shows the data of the questionnaire about the status quo of college English mobile teaching.

The first two items are designed to investigate the using status of mobile teaching platforms. Most students agree the frequency of use of mobile teaching platforms (19.05\% always, $51.19 \%$ usually, $23.21 \%$ sometimes). However, 6.55\% of respondents choose "seldom". As to whether the teacher can integrate multiple mobile teaching platforms effectively, $10.12 \%$ (8.93\% seldom, $1.19 \%$ never) of respondents are not satisfied. The data suggests that mobile teaching platforms should get used and integrated effectively. In teaching process, teachers should gradually discover the advantages and disadvantages of each platform, try to avoid its disadvantages, and choose teaching platform appropriately according to specific teaching content. At the same time, properly combining multiple 
Table 2. The questionnaire about the status quo of college English mobile teaching (\%).

\begin{tabular}{|c|c|c|c|c|c|}
\hline Items & $\begin{array}{l}\text { A } \\
\text { always }\end{array}$ & $\begin{array}{l}\text { B } \\
\text { usually }\end{array}$ & $\begin{array}{l}\mathrm{C} \\
\text { sometimes }\end{array}$ & $\begin{array}{l}\mathrm{D} \\
\text { seldom }\end{array}$ & $\begin{array}{l}\text { E } \\
\text { never }\end{array}$ \\
\hline $\begin{array}{l}\text { 1) The use of mobile teaching } \\
\text { platforms }\end{array}$ & 19.05 & 51.19 & 23.21 & 6.55 & 0 \\
\hline $\begin{array}{l}\text { 2) Integrate multiple mobile teaching } \\
\text { platforms effectively }\end{array}$ & 20.83 & 45.24 & 23.81 & 8.93 & 1.19 \\
\hline $\begin{array}{l}\text { 3) Have mobile teaching in traditional } \\
\text { classrooms }\end{array}$ & 13.21 & 41.32 & 43.59 & 1.88 & 0 \\
\hline $\begin{array}{l}\text { 4) Have well-equipped classrooms for } \\
\text { college English mobile learning }\end{array}$ & 25 & 37.5 & 21.43 & 12.5 & 3.57 \\
\hline $\begin{array}{l}\text { 5) Update mobile teaching } \\
\text { resources }\end{array}$ & 6.55 & 38.1 & 30.35 & 25 & 0 \\
\hline $\begin{array}{l}\text { 6) Get teacher's feedback in time on } \\
\text { mobile teaching platforms }\end{array}$ & 26.79 & 42.26 & 23.21 & 5.95 & 1.79 \\
\hline $\begin{array}{l}\text { 7) Have group discussions on mobile } \\
\text { teaching platforms }\end{array}$ & 10.71 & 24.4 & 40.48 & 24.41 & 0 \\
\hline $\begin{array}{l}\text { 8) Have peer evaluation on mobile } \\
\text { teaching platforms }\end{array}$ & 0 & 25.6 & 39.69 & 34.71 & 0 \\
\hline $\begin{array}{l}\text { 9) Have interest in learning on mobile } \\
\text { platforms }\end{array}$ & 17.86 & 47.62 & 27.98 & 4.76 & 1.78 \\
\hline $\begin{array}{l}\text { 10) Have tests on mobile teaching } \\
\text { platforms }\end{array}$ & 25.6 & 44.04 & 25.6 & 4.76 & 0 \\
\hline
\end{tabular}

teaching platforms will become a helpful supplement to traditional teaching, thus leading the teaching process more smoothly.

Items 3 and 4 show the status quo of mobile teaching environment. The data of Item 3 indicate that mobile teaching activities are usually (41.32\%) or sometimes $(43.59 \%)$ carried out in traditional classrooms. In Item 4, although $83.93 \%$ (25\% always, $37.5 \%$ usually, $21.43 \%$ sometimes) of respondents more or less agree that the university has well-equipped classrooms for college English mobile teaching. However, a fraction of respondents ( $12.5 \%$ seldom, $3.57 \%$ never) is still not satisfied with the equipment of mobile teaching. Due to the increasing enrollment and limited multimedia classrooms, students tend to be arranged to study Integrated English course in traditional classrooms, while Listening and Speaking course in multimedia classrooms. Good mobile teaching environment can guarantee the teaching effect of college English. In order to improve this situation, the researchers have applied for the university to expand the construction of multimedia classrooms and update some teaching facilities.

Items 5 and 6 reflect that the teacher terminal deserves to be optimized. In Item 5 , a striking data $25 \%$ (seldom) catches the researchers' attention. Mobile teaching resources can expand students' knowledge and integrate their fragmented time. Update teaching resources on the teaching platform is quite necessary. Meanwhile, the teaching resources should involve industry English 
knowledge. In Item 6, although most respondents are satisfied with teacher's feedback, $7.74 \%$ (5.95\% seldom, 1.79\% never) of respondents are not satisfied. That's maybe because of the big class size or the teacher's limited time. No matter what the reason is, the data actually indicate that teachers should give students effective feedback in time, so as to lead students to improve better.

Items 7 to 9 show mobile teaching methods are expected to get improved. Item 7 shows $24.41 \%$ (seldom) of respondents are not satisfied with group discussion. Item 8 shows $34.71 \%$ (seldom) of respondents are not satisfied with peer evaluation. No respondent chose "always". Item 9 shows $27.98 \%$ of respondents are usually interested in learning on mobile platforms, but $6.54 \%$ (4.76\% seldom, $1.78 \%$ never) of respondents still show their low interest or disinterest. The above data remind researchers that mobile teaching methods should be diverse. In order to involve as many students as possible in college English teaching, teachers should combine industry demand with general English teaching, and adopt many teaching methods, such as heuristic method, discussion method, research method, etc. Through adopting these methods in mobile teaching, teachers can develop student-centered teaching, cultivate students' inquiry and autonomous learning abilities, and also increase their learning interest.

Item 10 shows the test function of mobile teaching platforms. Testing on mobile teaching platforms is quite fair and efficient. It can save a lot of time for teachers. At the same time, it can examine students' study in time. However, according to the data, $4.76 \%$ of respondents chose "seldom". After investigation, researchers have found that students mainly have two big tests on mobile teaching platforms each semester. This is obviously not enough. To enhance students' English learning abilities, teachers should strengthen process evaluation. They can set some small tests for students based on specific teaching contents. The test contents should be industry-related. Through those tests, teachers can adjust teaching accordingly.

Table 3 is an interview after teaching reform and practice. It examines mobile teaching effect of college English oriented by industry demand.

After the optimization of college English mobile teaching oriented by industry demand, altogether 40 respondents are randomly selected to finish the interview.

Table 3. An interview after teaching reform and practice.

\begin{tabular}{lccc}
\hline \multicolumn{1}{c}{ Questions } & \multicolumn{2}{c}{ Total $(\mathrm{N}=40)$} \\
\cline { 2 - 4 } & Agree & Not sure & Disagree \\
\hline 1) Gain some industry-related English knowledge & 40 & 0 & 0 \\
2) Enhance vocational English skills & 38 & 2 & 0 \\
3) Improve mobile teaching environment & 34 & 4 & 1 \\
4) Develop interest in mobile learning resources & 36 & 3 & 3 \\
5) Motivate autonomous learning on mobile platforms & 31 & 6 & 2 \\
\hline
\end{tabular}


The result of Question 1 is quite ideal, as all the respondents agree that they have gained some industry-related English knowledge. In Question 2, most respondents (38) agree that the teaching reform has enhanced their vocational English skills. However, 2 respondents are not sure. That suggests vocational English skills should continue to get promoted in future English teaching. According to Question 3, mobile teaching environment has improved a lot, but it still needs to be improved further, as 4 respondents are not sure and 2 respondents disagree. In Question 4, 3 respondents are not sure whether the new teaching practice has developed their interest in mobile learning resources or not. Even one respondent chose "disagree". That's probably because the development of interest is a long process, plus the English level of respondents is quite different. Meanwhile, it also indicates teachers should explore more industry-related mobile learning resources. The result of Question 5 is relatively not satisfactory. 6 respondents are not sure and 3 respondents disagree. So teachers should continue cultivating students' autonomous learning ability, and further motivating their enthusiasm for autonomous learning on mobile platforms. Although the interview still reveals some deficiencies, in general, the mobile teaching reform of college English has made great progress.

\section{Conclusion}

Different from traditional English teaching, college English mobile teaching can break through the limitation of time and space, and realize diversified development of interactive teaching. From the above study, it can be seen that college English mobile teaching should be oriented by industry demand. Only by this way can universities cultivate more applied talents to meet the development of the industry and the society. The researchers have made a series of teaching reform to realize the effective combination of mobile teaching of college English with industry English knowledge. First, researchers realize the optimization of teacher terminal from several aspects, such as teaching content, test, feedback, evaluation, etc. Second, researchers realize the optimization of student terminal in group discussion, group activities, homework, peer evaluations, etc. Third, researchers realize the optimization of teaching process basically from three steps, i.e., before class, in the class, and after class.

Through the teaching reform, it is hoped to continuously improve the teaching effect of college English mobile teaching oriented by industry demand. A new teaching environment is expected to be constructed. Relations between teachers and students become more harmonious. Students become more enthusiastic and confident. Their English basic skills of listening, speaking, reading, writing and translating get promoted. They can gradually grasp basic vocational English knowledge. Meanwhile, college English teachers also become more competent in cultivating applied talents.

Due to the optimizing construction of college English mobile teaching oriented by industry demand is a relatively new research perspective, some detailed 
measures to solve deficiencies in the interview after teaching reform and practice need to get further proved in future teaching. Therefore, the study deserves in-depth exploration in the future.

\section{Funding}

The research is supported by Baoding University Foundation Project for Transformation Development Research: Optimizing the Construction of College English Mobile Teaching Oriented by Industry Demand. Project number: 2019J01.

\section{Conflicts of Interest}

The authors declare no conflicts of interest regarding the publication of this paper.

\section{References}

Brindley, G. (1989). The Role of Needs Analysis in Adult ESL Program Design (pp. 63-78). In R. K. Johnson (Ed.), The Second Language Curriculum. Cambridge: CUP. https://doi.org/10.1017/CBO9781139524520.007

Ekanayake, S. Y., \& Wishart, J. (2015). Integrating Mobile Phones into Teaching and Learning: A Case Study of Teacher Training through Professional Development Workshops. British Journal of Educational Technology, 46, 173-189. https://doi.org/10.1111/bjet.12131

He, L. Z. (2020). New Requirements for College English Teaching in the New Era-Revision of College English Teaching Guidelines: Rationale and Highlights. Foreign Language World, 4, 13-18.

Hutchinson, T., \& Waters, A. (1987). English for Specific Purposes. New York: Cambridge University Press. https://doi.org/10.1017/CBO9780511733031

Keengwe, J., \& Bhargava, M. (2014). Mobile Learning and Integration of Mobile Technologies in Education. Education \& Information Technologies, 19, 737-746. https://doi.org/10.1007/s10639-013-9250-3

Lindner, M., \& Bruck, P. A. (2004). Micromedia and Corporate Learning (p. 8). In Proceedings of the 3rd International Micro Learning 2007 Conference. Innsbruck: Innsbruck University Press.

Ministry of Education of the People's Republic of China (2018). Education Informatization 2.0 Action Plan. http://www.moe.gov.cn/

Munby, J. (1978). Communicative Syllabus Design. Cambridge: CUP.

Rahman, M. (2015). English for Specific Purposes (ESP): A Holistic Review. Universal Journal of Educational Research, 3, 24-31. https://doi.org/10.13189/ujer.2015.030104

Shu, D. F. (2004). ELT in China: Problems and Suggested Solutions. Shanghai: Shanghai Foreign Language Education Press. 